Article

\title{
The Role of the Process and Design Variables in Improving the Performance of Heat Exchanger Tube Expansion
}

\author{
Changwan Han ${ }^{\dagger}$, Inchul Sin ${ }^{\dagger}$, Hyerin Kwon and Seonghun Park ${ }^{*}$ \\ School of Mechanical Engineering, Pusan National University, 30 Jangjeon-dong, Geumjeong-gu, Busan 609-735, \\ Korea; hwchangwan@pusan.ac.kr (C.H.); invida@naver.com (I.S.); khr3434@naver.com (H.K.) \\ * Correspondence: paks@pusan.ac.kr; Tel.: +82-51-510-2330; Fax: +82-51-514-0685 \\ + These authors contributed equally to this work.
}

Received: 26 March 2018; Accepted: 9 May 2018; Published: 10 May 2018

\begin{abstract}
In the expansion process of a fin-tube heat exchanger, the process variables and shape of the expansion ball affect the deformation of the tube's inner grooves, the adhesion, and the expansion force. These factors influence the efficiency of heat transfer and the lifetime of the expansion equipment. Therefore, this study analyzed the influential variables of the tube expansion process as well as the expansion ball design through experiments and simulations. A new method was proposed to determine the severity of adhesion in the tube's inner grooves using the expansion force rate. Expansion experiments with $\mathrm{Al}$ tubes show that the expansion force decreases when using a lubricant with high viscosity and when the lubricant remains on the expansion ball for a longer duration. Finite element analysis was also performed to examine the expansion of $\mathrm{Cu}$ tubes, which showed that the expansion force was higher when using expansion ball shapes that have higher contact area between the ball and tube surface. The radius of curvature of the expansion ball also influenced the expansion force. However, increasing the ratio of the radial force to the expansion force increased the deformation of the tube's inner grooves.
\end{abstract}

Keywords: tube expansion; Inner grooved tube; $\mathrm{Al}$ and $\mathrm{Cu}$ tubes; expansion ball design; fin-tube heat exchanger

\section{Introduction}

Fin-tube heat exchangers are widely used [1], and a tube with a carved inner groove has been used to improve the tube's heat transfer performance [2]. For the assembly of fin-tube heat exchangers, a tube with a smaller diameter than the inside of the fin is first inserted inside the fin and then expanded to secure tight contact between the fin and tube using an expansion ball. However, in this process, the heat transfer efficiency decreases because of the change in the shape of the groove. Accordingly, many researchers have attempted to improve the expansion process.

Previous studies have examined the influence of the expansion speed and expansion ratio (the ratio of the outer tube diameters before and after expansion) on the tube crease generation, expansion force, and heat transfer efficiency. Almeida et al. investigated the optimum expansion ratio to minimize the occurrence of tube crease [3]. Pervez et al. analyzed the expanded tube thickness and the expansion force according to the expansion ratio [4]. Numerical simulations were used to study the effect of the expansion ratio on the gap between the tube and the fin and on the thermal conductance after expansion [5]. Although the speed of the expansion ball did not have a large effect on the expansion force [6], the geometry tolerances produced when manufacturing the tube can compromise the heat transfer performance [7]. The friction between the expansion ball and the tube is the most significant 
factor for increasing the expansion force, which was accurately predicted numerically when the applied friction coefficient was below 0.3 [8]. In a numerical study, Lee et al. observed that non-uniform height of the tube's inner grooves provided better contact pressure between the tube and fin after expansion [9]. Previous studies also investigated the influence of the slope angle on the expansion force [10] and on the formation of tube creases [11,12]. The effect of the expansion ball curvature on the expansion force and tube's inner groove deformation has also been studied [13,14]. Elliptical, hemispherical, and conical expansion ball shapes influence the expansion force during expansion and the tube thickness after expansion [15], and the size and operating interface temperatures affect the heat transfer efficiency [16].

Despite the considerable amount of research, there is still a great demand in the industry for an increase in the heat exchanger efficiency that can reduce production and maintenance costs and improve the performance. Therefore, this study focused on increasing the heat exchanger performance by minimizing both the deformation of the tube's inner grooves and the expansion force in the tube expansion process whose minimizations were considered as the expansion performance in this study. To achieve this goal, we first determined the variables that had a significant impact on the expansion performance and then analyzed their role in the expansion performance through experiments and numerical analyses. A new method has also been proposed to determine the severity of adhesion of tube's inner grooves using the expansion force rate.

\section{Materials and Methods}

\subsection{Materials}

Al3003-O aluminum tubes (7.1-mm outer diameter and 0.44-mm thickness) were used in expansion experiments, while C1220-O copper tubes (5-mm outer diameter and 0.2-mm thickness) were used in finite element (FE) analyses. The material of the fins was Al3003-O in the experiments and FE analyses. The expansion balls were made of stainless steel (SS304), and a diamond coating was applied to decrease the friction between the tube and ball surface.

For the FE analyses, the stress and strain curves of the tube and fin were obtained experimentally using 120-mm Al and $\mathrm{Cu}$ tubes in tensile experiments with a tensile testing machine (Model 310 R\&B Company Ltd., Dajeon, Korea). Tensile experiments were performed on the $\mathrm{Al}$ and $\mathrm{Cu}$ tubes with a gauge length of $100 \mathrm{~mm}$ at a load speed of $0.1 \mathrm{~mm} / \mathrm{s}$ while gradually increasing the load until the occurrence of fractures (Figure 1a). In the current study, we have measured strain from the change in the grip-to-grip length relative to the initial grip-to-grip length. The results of the tensile experiments revealed that the $\mathrm{Al}$ and $\mathrm{Cu}$ tubes had fractures in the central area. The stress-strain curves are shown in Figure 1b.

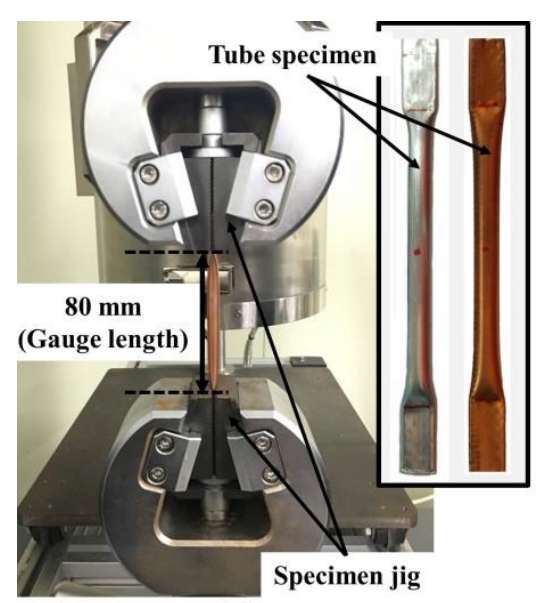

(a)

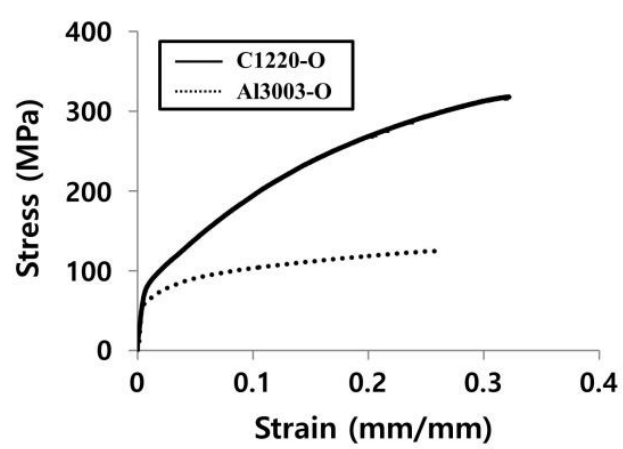

(b)

Figure 1. Cont. 


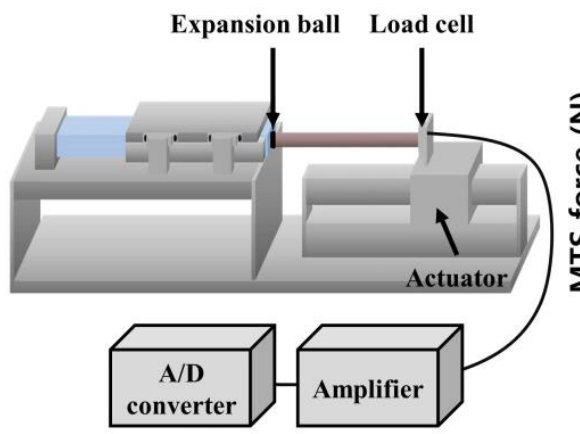

(c)

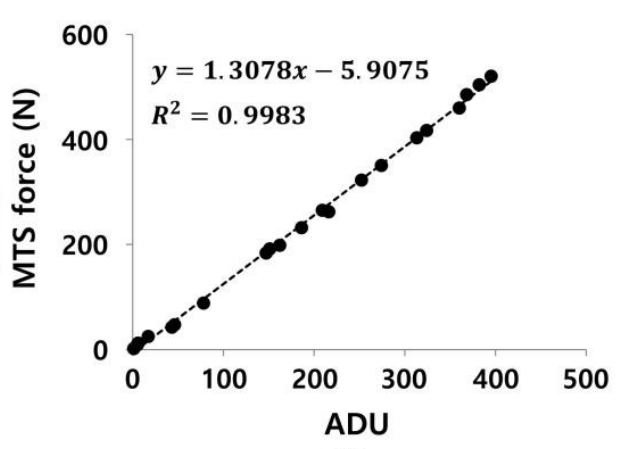

(d)

Figure 1. (a) Tensile test grips installed with specimens; (b) stress-strain curves of Al3003-O and C1220-O specimens; (c) schematic of Al tube expansion experiments; and (d) calibration of load cell used in the tube expansion experiments by correlating with the load values measured through an MTS device.

\subsection{Experimental Methods}

Our previous study predicted the adhesion locations by comparing the differentiation of expansion force in terms of time (i.e., expansion force rate) with measurements of the tube's inner groove adhesion, because the sudden increase in the expansion force has a close relation to the occurrence of adhesion in the tube's inner grooves during the expansion [17]. In the present study, a custom expansion experimental device was made with a jig to position the tube, a 1-axis current controller (RCS-6000G, Robostar, South Korea), a 100-kgf load cell (CDFS-100, Bongshin, Gyeonggi-do, Korea), a 12-bit A/D converter (VSAD-101, Visol, Gyeonggi-do, Korea), and signal amplifiers. For the expansion experiments, an expansion ball was inserted into the tube after fastening it to the device, and then the tube was expanded (Figure 1c). The expansion force profiles were measured from the reaction force generated in the expansion ball in the direction of expansion. Then, the expansion force was calculated by the maximum value of each expansion force profile.

The expansion force rate and its standard deviation were obtained to investigate the effect of the expansion force magnitude on the amount of adhesion. The expansion force profiles were recorded as an analog signal and converted to a digital signal (ADU, $1 \mathrm{ADU}=20 / 4096$ volts) using commercial software (Kwon GRF, Visol, Gyeonggi-do, Korea). The 100-kgf load cell was calibrated using ADU values acquired with 25 cycles of a sinusoidal load at $10 \mathrm{~Hz}$ with a stress ratio of 0.1 (50-500 N). The results were then compared with load values obtained from a 200-kgf capacity load cell (BCA-200, TESTA, Busan, Korea) installed in an MTS machine (MTS 810, MTS Systems Corp., Eden Prairie, MN, USA). The following linear calibration equation was obtained: Load $(\mathrm{N})=1.3078 \times$ ADU -5.9057 (Figure 1d).

Next, expansion experiments were done to analyze the effect of the expansion speed, lubricant viscosity, and expansion ball shape on the expansion force. Different process variables and ball shapes were examined. In the notation of the experimental groups, " $\mathrm{G}$ " represents a grooved ball, "S" indicates a smooth ball, " 1 " represents expansion at $1 \mathrm{~m} / \mathrm{s}$, and " 05 " indicates $0.5 \mathrm{~m} / \mathrm{s}$. " $\mathrm{N}$ " indicates that no lubricant is used, " $\mathrm{A}$ " indicates DH173A lubricant $\left(0.9 \mathrm{mPa} \cdot \mathrm{s}\right.$ at $\left.20^{\circ} \mathrm{C}\right)$, and " $\mathrm{H}$ " indicates $\mathrm{DH} 23 \mathrm{H}\left(2.9 \mathrm{mPa} \cdot \mathrm{s}\right.$ at $\left.20^{\circ} \mathrm{C}\right)$ (Table 1$)$. The expansion experiment results of the $\mathrm{S} 1 \mathrm{H}$ and $\mathrm{S} 05 \mathrm{H}$ groups were compared to investigate the effect of the expansion speed on the expansion force and adhesion; the experiments with groups $\mathrm{S} 1 \mathrm{H}$ and $\mathrm{S} 1 \mathrm{~A}$ were done to analyze the effect of the lubricant type; and those with groups G1N and S1N were used to determine the influence of the lubricant groove (Table 1). 
Table 1. Experimental groups for Al tube expansion experiments.

\begin{tabular}{cccc}
\hline Experimental Group & Expansion Speed $(\mathrm{m} / \mathbf{s})$ & Lubricant & Expansion Ball Shape \\
\hline G1N & 1 & Non-lubricated & Grooved \\
S1N & 1 & Non-lubricated & Smooth \\
S1A & 1 & DH173A & Smooth \\
S1H & 1 & DH23H & Smooth \\
S05H & 0.5 & DH23H & Smooth \\
\hline
\end{tabular}

\subsection{FE Analysis Methods}

\subsubsection{Validation of Finite Element Analysis}

To ensure the reliability of the FE analysis, the expansion force results of the G1N and S1N groups were compared with those obtained from an FE analysis under the same conditions. The grooved and smooth ball models for the G1N and S1N groups were modeled using Rhino3D (Robert McNeel \& Associates, Seattle, WA, USA) (Figure 2). A hexahedron with eight nodes was used for the Al tube model mesh, and a total of 22,523 nodes and 19,000 elements were produced. For FE analyses, a 1/20 cyclic symmetry condition was applied based on the x-axis to decrease the analysis time (DEFORM-3D, Scientific Forming Technologies Corporation, Columbus, OH, USA). The expansion ball was assumed to be rigid, and the expansion speeds were $1 \mathrm{~m} / \mathrm{s}$ and $0.5 \mathrm{~m} / \mathrm{s}$.

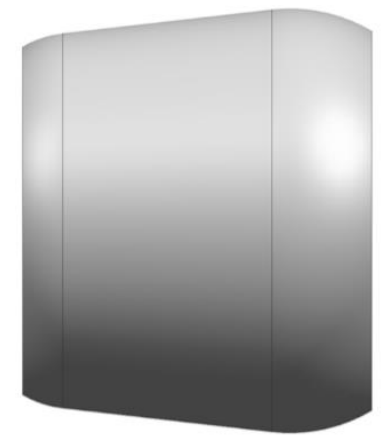

(a)

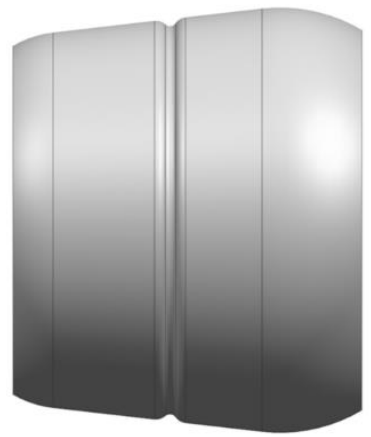

(b)

Figure 2. Three-dimensional models of: (a) a smooth expansion ball; and (b) grooved ball with a lubricant groove on its surface for $\mathrm{Al}$ tube expansion experiments.

To select the proper friction coefficient for the FE analysis, the expansion force results from FE analyses using three friction coefficients that were selected based on previous studies (i.e., $0.2,0.3$ and $0.45)[18,19]$ were compared with those from expansion experiments. The steady-state values of the expansion force profiles from FE analyses were similar to those from the experiments when the friction coefficient between the expansion ball and $\mathrm{Al}$ tube was 0.3 (Figure 3a). The maximum expansion force of S1N was $245.1 \mathrm{~N}$ in the FE analysis and $267.0 \mathrm{~N}$ in the experiment (an $8.2 \%$ difference). The maximum expansion force of G1N was $247.7 \mathrm{~N}$ in the FE analysis and $274.8 \mathrm{~N}$ in the experiment (a 9.9\% difference). However, the transient response of the expansion force profiles was different between the $\mathrm{FE}$ analyses and experiments due to the viscoelastic nature of the $\mathrm{Al}$, which was not considered in the FE analysis. For the steady-state response, however, the experimental expansion force profiles showed a little oscillation, which could have been possibly due to a change in the friction coefficient between the expansion ball and tube during expansion. There was negligible oscillation in the analytical force profiles when using a fixed friction coefficient, but the average force values of the steady-state response were quite comparable between the experiments and simulations. The change in the friction coefficient during the tube expansion in the experiments could have occurred for various reasons, including changes in the expansion-driving actuator speeds and adhesion of the tube's inner grooves (Figure 3b). 


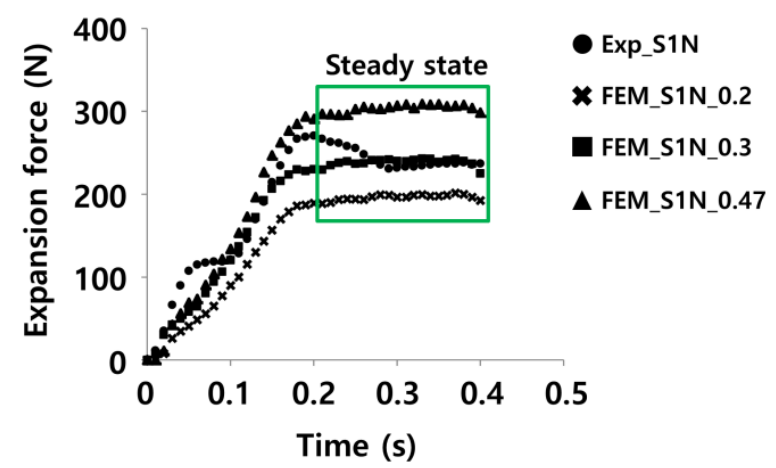

(a)

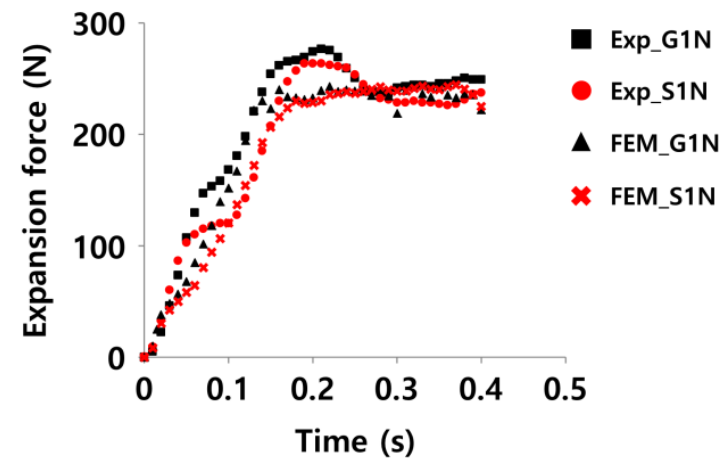

(b)

Figure 3. (a) Effects of friction coefficients $(0.2,0.3,0.47)$ on expansion forces for the S1N group; and (b) comparisons of expansion forces between the expansion experiments and FE analyses for the S1N and G1N groups.

\subsubsection{FE Analysis of $\mathrm{Cu}$ Tube Expansion}

Expansion Ball Geometry

The effect of the expansion ball shape was investigated using an expansion ball without grooves on the surface (Type 1) and one with grooves (Type 2). The groove size was based on the size of the tube's inner grooves. The Type 2 ball has 40 grooves for distributing the applied load by increasing the contact area between the ball and tube surface. The Type 3 ball was generated by reducing the grooves' top width $(W)$ from $0.2 \mathrm{~mm}$ to $0.1 \mathrm{~mm}$ to analyze the influence of the contact area. For Type 4, an additional free gap $(H=0.1 \mathrm{~mm})$ was made between the ball and tube-groove peak point on Type 3 to remove the contact point between the tube-groove and ball. Type 5 was produced by decreasing the number of expansion ball grooves of Type 3 from 40 to 20. Type 6 and Type 7 were designed with surface radii of $R=5.3 \mathrm{~mm}$ and $R=7.9 \mathrm{~mm}$, respectively, and without expansion ball grooves to analyze the influence of the radius of curvature $R$ on the tube expansion performance (Figure 4 and Table 2).

Table 2. Design variables for different expansion ball shapes.

\begin{tabular}{ccccc}
\hline Expansion Ball Type & Groove Number & $\mathbf{W}(\mathbf{m m})$ & $\mathbf{H}(\mathbf{m m})$ & $\mathbf{R}(\mathbf{m m})$ \\
\hline Type 1 & 0 & 0 & 0 & 5.7 \\
Type 2 & 40 & 0.2 & 0 & 5.7 \\
Type 3 & 40 & 0.1 & 0 & 5.7 \\
Type 4 & 40 & 0.1 & 0.1 & 5.7 \\
Type 5 & 20 & 0.1 & 0 & 5.7 \\
Type 6 & 0 & 0 & 0 & 5.3 \\
Type 7 & 0 & 0 & 0 & 7.3 \\
\hline
\end{tabular}




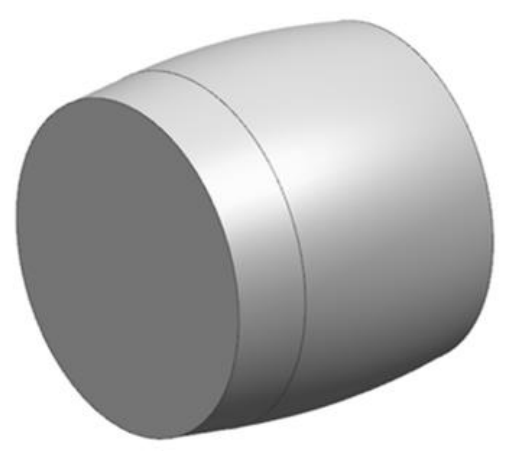

(a)

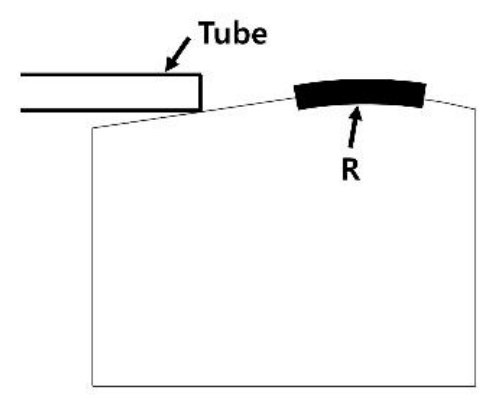

(c)

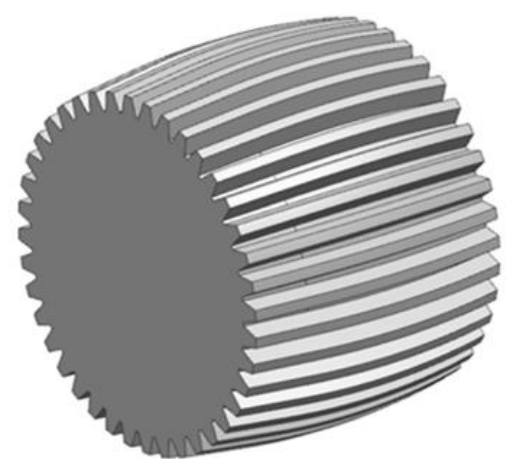

(b)

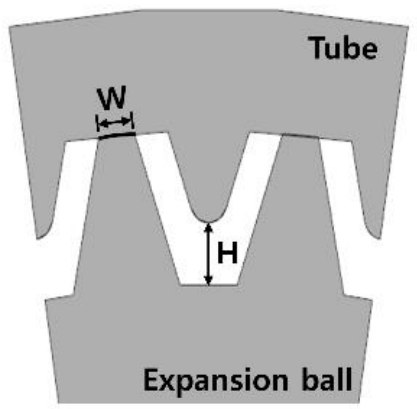

(d)

Figure 4. (a) Three-dimensional models of a smooth expansion ball (Type 1); (b) an expansion ball with expansion grooves on its surface for distributing concentrated load on the tube's inner grooves during the tube expansion (Types 2-5); (c) schematic of expansion balls with the radius of curvature $R$ as the design variable (Types 6 and 7); and (d) definitions of width $(W)$ of the expansion ball groove and gap $(H)$ between the valley of the expansion ball groove and the peak of the tube's inner groove.

FE Analysis

Similar to the validation FE analysis of the $\mathrm{Al}$ tube expansion (Section 2.3.1), a hexahedron with eight nodes was used for the mesh in Cu tube models. Accordingly, 42,634 nodes and 30,220 elements were produced, and a 1/20 cyclical symmetry condition was applied based on the $x$-axis. The tube ends were constrained to the direction of expansion (x-axis in Figure 5) to replicate no tube shrinkage condition during actual tube expansion. The fin combined with the tube was constrained to the upper side (the y-direction in Figure 5). The same expansion ball speed of $90 \mathrm{~mm} / \mathrm{s}$ as in the actual tube expansion process was applied, along with a friction coefficient of 0.36 between the expansion ball and Cu tube [12].

After the tube expansion analysis, reference points P1 and P2 were selected at the peak and valley of the tube's inner groove, respectively. The tube's inner groove deformation $(\Delta \mathrm{P} 2-\Delta \mathrm{P} 1)$ was determined by the difference between $\mathrm{P} 1$ and $\mathrm{P} 2$ before and after measuring the displacement of the two points. In the FE analyses, the expansion force was computed using the average of the steady-state values, which occurred at approximately $0.03-0.11 \mathrm{~s}$ in the axial direction of expansion. The radial force was measured in the radial direction of the tube expansion (Figure 5). 


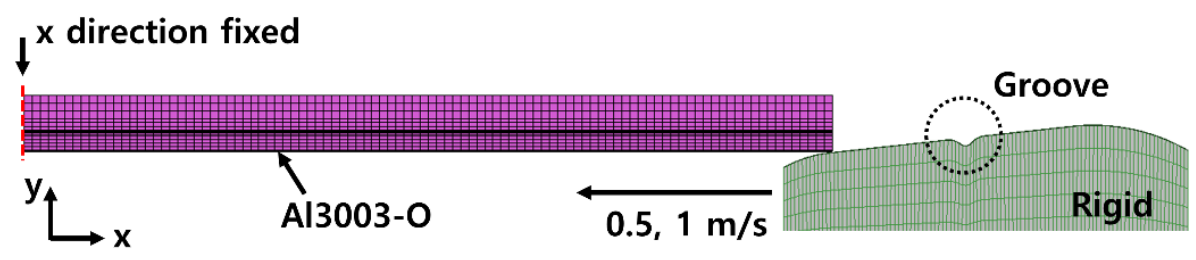

(a)

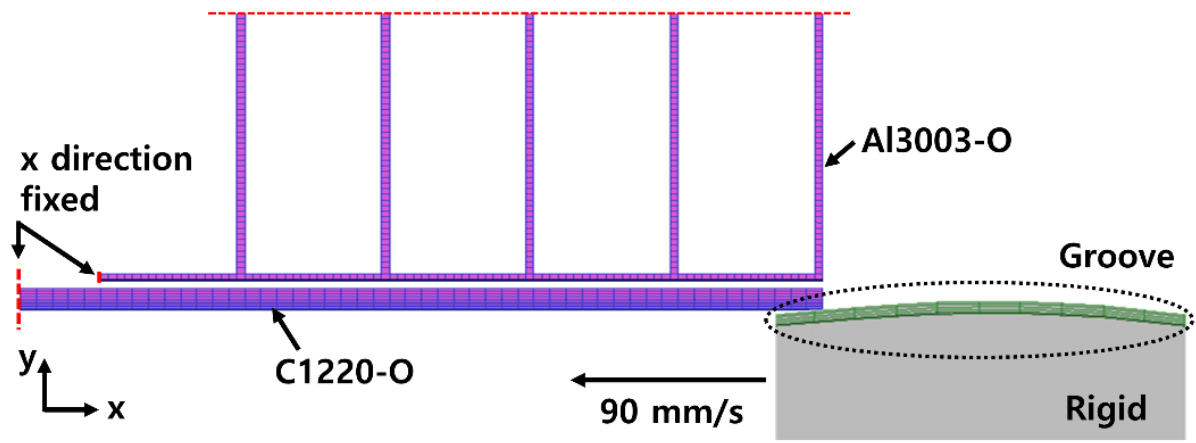

(b)

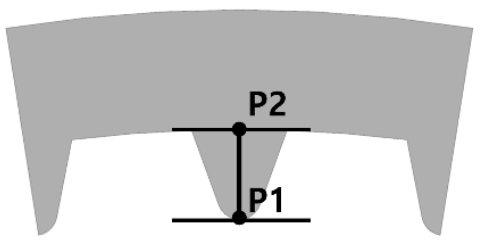

(c)

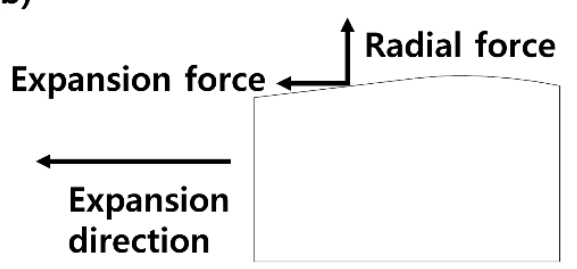

(d)

Figure 5. FE models and boundary conditions for the analysis of (a) $\mathrm{Al}$ tube and (b) Cu tube expansions; (c) reference points P1 and P2 for calculating the tube's inner groove deformation; and (d) axial and radial forces.

\subsection{Statistical Analysis}

A one-way analysis of variance (one-way ANOVA) was performed using commercial software (Excel, Microsoft, Seattle, WA, USA). The analysis was carried out to determine whether there was a statistically significant difference in the expansion force between the two different expansion speeds $(0.5 \mathrm{~m} / \mathrm{s}$ and $1 \mathrm{~m} / \mathrm{s})$, between the two lubricant types with different viscosities (DH173A and DH23H), and between the two expansion balls with and without the lubricant groove. The significance level was set at $\alpha=0.05$.

\section{Results and Discussion}

\subsection{Al tube Expansion Experiments}

In the $\mathrm{Al}$ tube expansion experiments, the expansion force was $\sim 442 \mathrm{~N}$ for $\mathrm{S} 1 \mathrm{H}$ with an expansion speed of $1 \mathrm{~m} / \mathrm{s}$. The expansion force for $\mathrm{S} 05 \mathrm{H}$ was $\sim 439 \mathrm{~N}$ with a speed of $0.5 \mathrm{~m} / \mathrm{s}$. These results indicate that the speed had no influence on the expansion force $(p=0.58)$. The expansion force of G1N was $\sim 519 \mathrm{~N}$, while that of S1N was $\sim 561 \mathrm{~N}(p=0.27)$. Although there was no statistical difference in these results, there was a slight decrease in the expansion force with the lubricant groove on the expansion ball (G1N). This might have been caused by a decrease in the friction force due to the better lubricant supply. There was a significant difference in the expansion force between S1N $(\sim 561 \mathrm{~N})$, which used no lubricant, and S1H ( 442 N), which used the DH23H lubricant $(p \cong 0.00)$. S1A used the DH173A lubricant, which has approximately three times lower viscosity than $\mathrm{DH} 23 \mathrm{H}$. The expansion force of S1A was $\sim 462 \mathrm{~N}$, which was approximately $5 \%$ higher than that of $\mathrm{S} 1 \mathrm{H}(p \cong 0.00)$. This result suggests the lubricants could decrease the friction between the expansion ball and tube, and lubricants 
with higher viscosity could stick to the ball surface for a longer time, resulting in more reduction in the expansion force (Figure 6a).

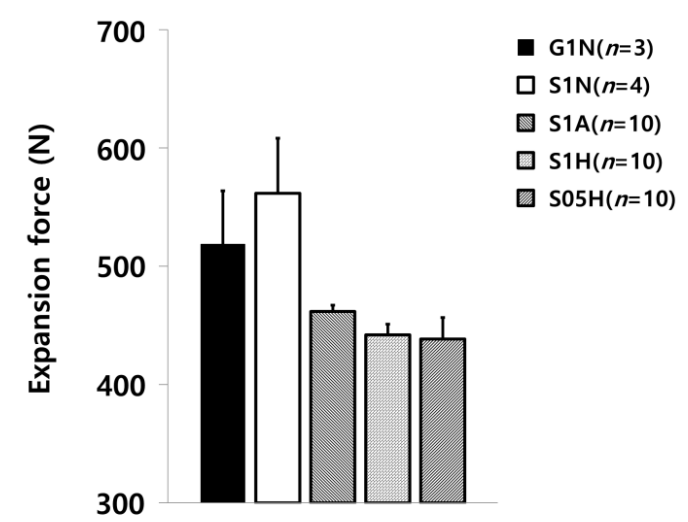

(a)

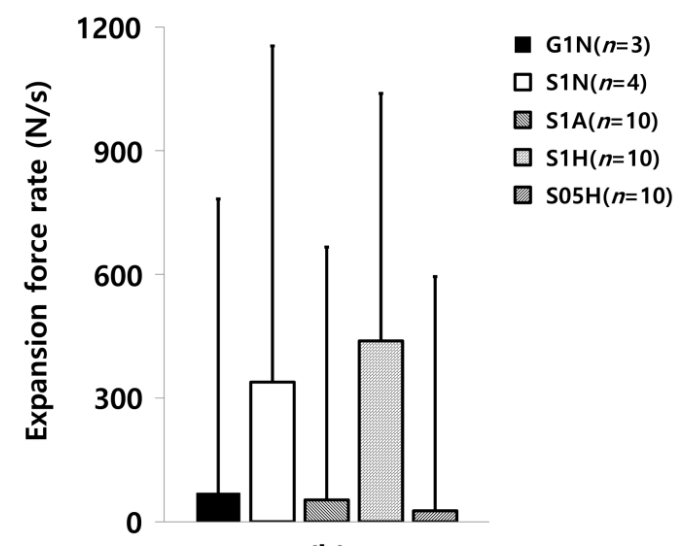

(b)

Figure 6. Al tube expansion experiment results: (a) expansion force; and (b) expansion force rate.

The expansion force rate, which is differentiation of the expansion force with respect to time, can be used to represent the occurrence of adhesion in the tube's inner grooves [17]. The standard deviation of the rate was the highest for $\mathrm{S} 1 \mathrm{~N}(\sim 815 \mathrm{~N} / \mathrm{s})$, which also produced the highest expansion force. However, the standard deviation of $\mathrm{S} 05 \mathrm{H}$, which had the lowest expansion force, was $\sim 568 \mathrm{~N} / \mathrm{s}$ (Figure $6 \mathrm{~b}$ and Table 3). According to our previous study [17], the adhesion of tube's inner grooves can be associated with the standard deviation of the expansion force rate, because the sudden increase in the expansion force has a close relation to the occurrence of adhesion in the tube's inner grooves during the expansion. In the current study, a linear correlation $\left(R^{2}=0.984\right)$ was observed between the expansion force and the expansion force rate's standard deviations (Figure 7). This result indicates that because a large expansion force can lead to a large deformation of the tube's inner grooves, the tube's inner groove deformation, which is difficult to be experimentally measured, can be estimated by calculating the standard deviation of the expansion force rate.

Table 3. Expansion force rate calculated by the average of each expansion force rate profile.

\begin{tabular}{ccc}
\hline Experimental Group & Expansion Force Rate (N/s) & STD of Expansion Force Rate (N/s) \\
\hline G1N $(n=3)$ & 69.6 & 713.4 \\
S1N $(n=4)$ & 338.8 & 815.2 \\
S1A $(n=10)$ & 53.0 & 613.1 \\
S1H $(n=10)$ & 438.7 & 600.2 \\
S05H $(n=10)$ & 26.8 & 567.9 \\
\hline
\end{tabular}




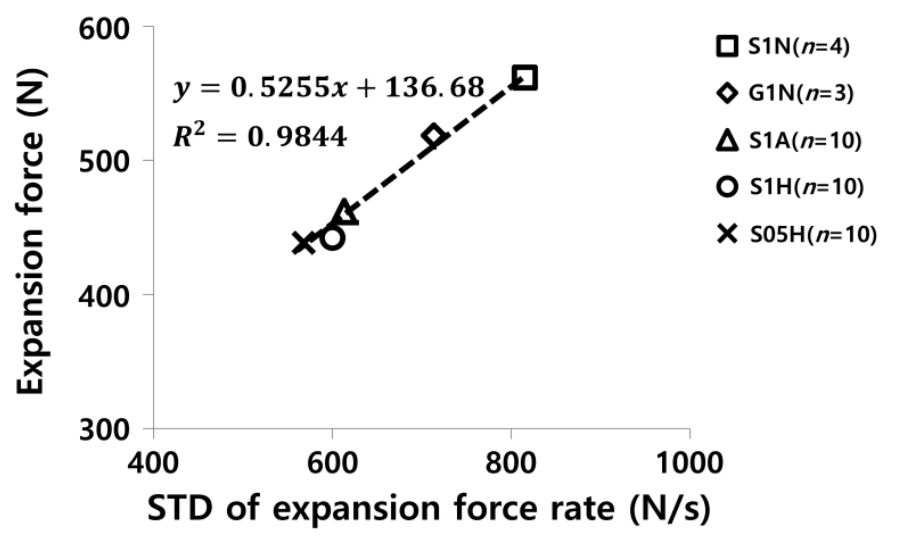

Figure 7. Correlation between the expansion force and standard deviation of the expansion force rate from Al tube expansion experiments.

\subsection{Cu Tube Expansion Analysis}

The expansion force and $\mathrm{Cu}$ tube's inner groove deformation $(\Delta \mathrm{P} 2-\Delta \mathrm{P} 1)$ were $104.8 \mathrm{~N}$ and $-0.007 \mathrm{~mm}$, respectively, from the FE analysis of $\mathrm{Cu}$ tube expansion using the Type 1 ball. For Type 2, the expansion force and $\Delta \mathrm{P} 2-\Delta \mathrm{P} 1$ were $270.5 \mathrm{~N}$ (158\% higher than Type 1$)$ and $-0.003 \mathrm{~mm}(57 \%$ lower than Type 1), respectively. This result suggests that the contact area between the tube and the expansion ball plays an important role in reducing tube's inner groove deformation, because Type 2, which has expansion ball grooves, has larger contact area than Type 1 and hence was effective in dispersing the stress produced in the tube's inner grooves. However, the increased contact area produces the increased friction force between the tube and the expansion ball, which results in an increase in the expansion force.

For the Type 3 ball, the expansion force and $\Delta \mathrm{P} 2-\Delta \mathrm{P} 1$ were $138.3 \mathrm{~N}(49 \%$ lower than Type 2$)$ and $-0.004 \mathrm{~mm}$ ( $25 \%$ higher than Type 2), respectively. This results also could be explained with respect to the contact area between the tube and ball. The contact area between the tube and Type 3 ball was smaller than that between the tube and Type 2 ball, as the width (W) of the Type 3 ball groove decreased. This smaller contact area for Type 3 produced the expansion force lower and $\Delta \mathrm{P} 2-\Delta \mathrm{P} 1$ higher than Type 2.

For Type 4 , the expansion force and $\Delta \mathrm{P} 2-\Delta \mathrm{P} 1$ were $131.8 \mathrm{~N}$ (5\% lower than Type 3 ) and $-0.001 \mathrm{~mm}$ (75\% lower than Type 3), respectively. This occurred because there was no contact between the expansion ball and the tube's inner groove peaks for Type 4, which led to a significant decrease in $\Delta \mathrm{P} 2-\Delta \mathrm{P} 1$. The expansion force slightly decreased due to a decrease in the contact area between the tube and ball (Figure 8, Table 4).

For Type 5, the expansion force and $\Delta \mathrm{P} 2-\Delta \mathrm{P} 1$ were $115.5 \mathrm{~N}(30 \%$ lower than Type 3$)$ and $-0.005 \mathrm{~mm}$ ( $40 \%$ higher), respectively. Similar to the above results, this result also occurred because the contact area between the tube and Type 5 ball was smaller compared to Type 3 due to the fewer grooves in Type 5 than in Type 3.

For Type 6, the expansion force and $\Delta \mathrm{P} 2-\Delta \mathrm{P} 1$ were $91.6 \mathrm{~N}$ and $-0.008 \mathrm{~mm}$, respectively. For Type 7 , the expansion force and $\Delta \mathrm{P} 2-\Delta \mathrm{P} 1$ were $88.9 \mathrm{~N}$ (3\% lower than Type 6) and $-0.006 \mathrm{~mm}(25 \%$ lower than Type 6), respectively. This result was caused by the curved surface of Type $7(R=7.9 \mathrm{~mm})$ which was smoother than that of Type $6(R=5.3 \mathrm{~mm})$. Therefore, the Type 7 ball was effective in dispersing the load generated in the tube's inner grooves, resulting in a decrease in $\Delta \mathrm{P} 2$. For Type 6 , the expansion force and $\Delta \mathrm{P} 2-\Delta \mathrm{P} 1$ were $91.6 \mathrm{~N}$ and $-0.008 \mathrm{~mm}$, respectively. The $\Delta \mathrm{P} 1$ compared to Type 6 (Figure 9 and Table 4). 


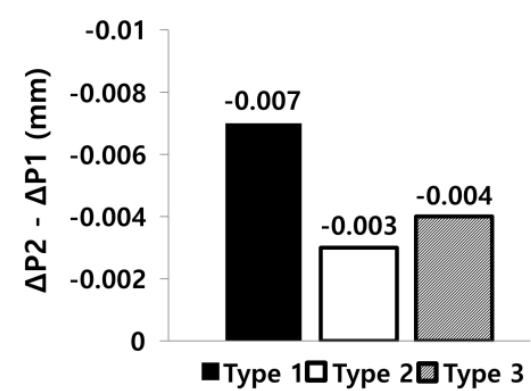

(a)

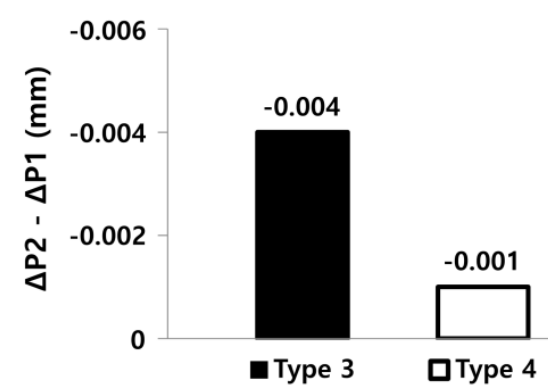

(c)

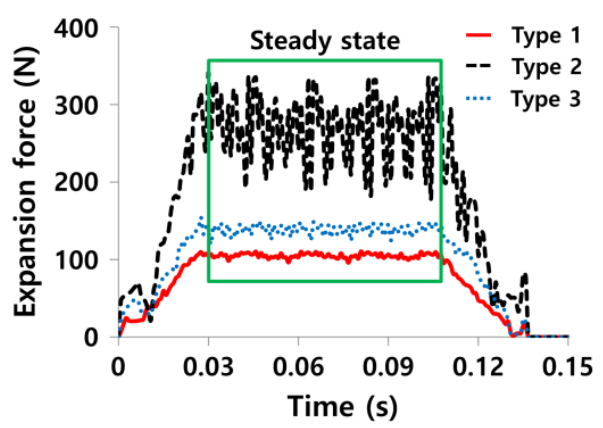

(b)

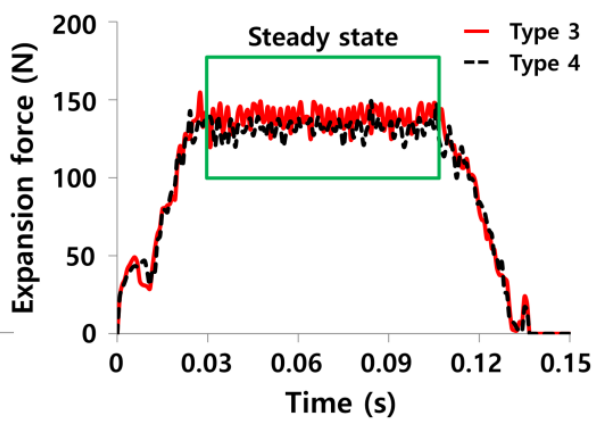

(d)

Figure 8. (a) $\Delta \mathrm{P} 2-\Delta \mathrm{P} 1$ of Type 1-3 expansion balls and (b) their expansion force profiles; and (c) $\Delta \mathrm{P} 2$ $-\Delta \mathrm{P} 1$ of Type 3 and 4 expansion balls and (d) their expansion force profiles.

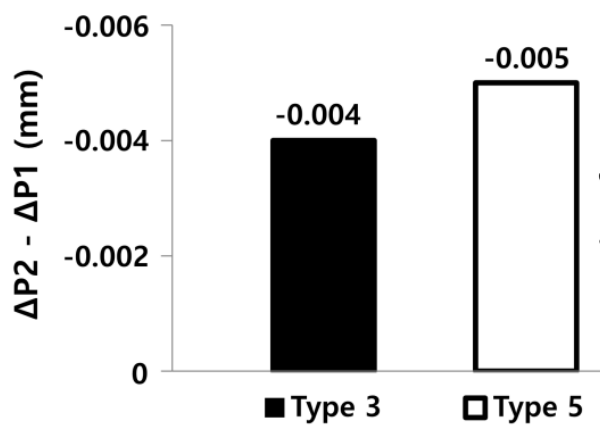

(a)

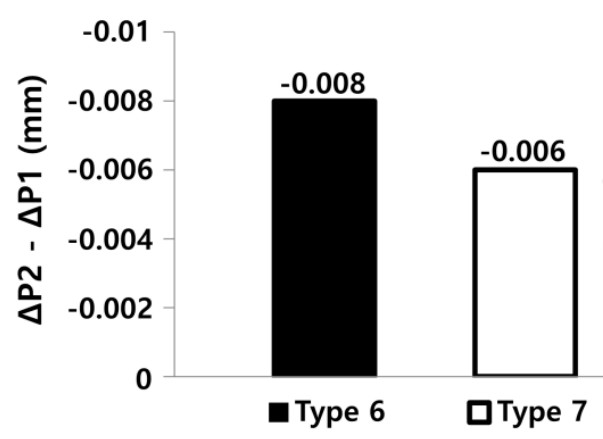

(c)

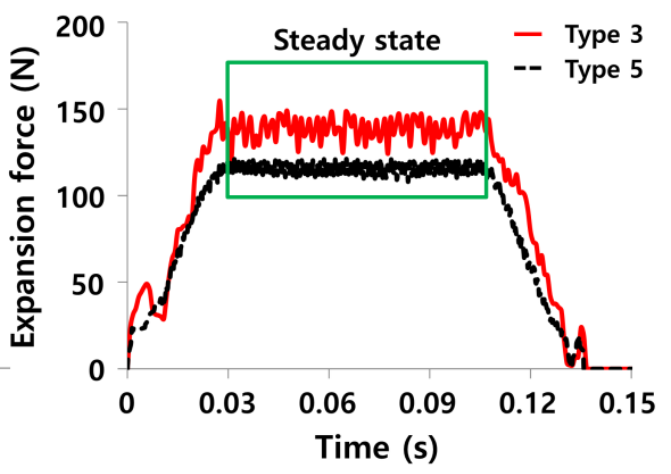

(b)

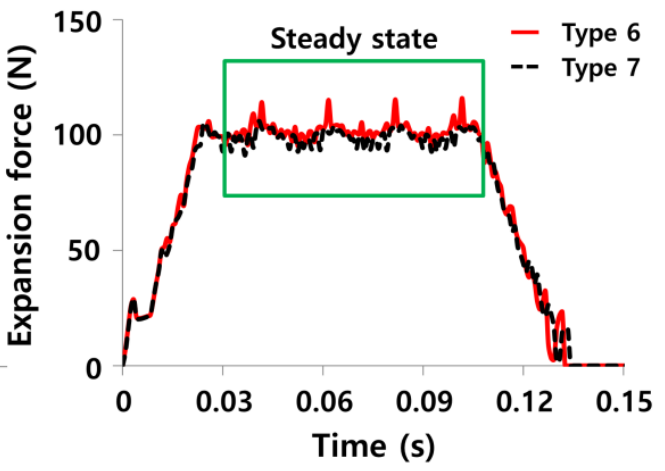

(d)

Figure 9. (a) $\Delta \mathrm{P} 2-\Delta \mathrm{P} 1$ of Type 3 and 5 expansion balls and (b) their expansion force profiles; and (c) $\Delta \mathrm{P} 2-\Delta \mathrm{P} 1$ of Type 6 and 7 expansion balls and (d) their expansion force profiles. 
Table 4. Expansion force measured from $\mathrm{Al}$ tube expansion experiments and $\mathrm{Cu}$ tube expansion analyses and the deformation of tube's inner grooves calculated from $\mathrm{Cu}$ tube expansion analyses.

\begin{tabular}{ccccc}
\hline Product & $\begin{array}{c}\text { Measurement } \\
\text { Method }\end{array}$ & Group & $\begin{array}{c}\text { Expansion Force } \\
\mathbf{( N )}\end{array}$ & $\begin{array}{c}\text { Tube's Inner Groove } \\
\text { Deformation }(\boldsymbol{\Delta P 2}-\boldsymbol{\Delta P 1})(\mathbf{m m})\end{array}$ \\
\hline \multirow{4}{*}{ Aluminum tubes } & Expansion & S1N $(n=3)$ & $518.5 \pm 46.6$ & - \\
& experiments & S1A $(n=10)$ & $561.3 \pm 44.8$ & - \\
& & S1H $(n=10)$ & $461.8 \pm 5.3$ & - \\
& S05H $(n=10)$ & $438.5 \pm 17.9$ & - \\
\hline \multirow{5}{*}{ Copper tubes } & Type 1 ball & 104.8 & -0.007 \\
& & Type 2 ball & 270.5 & -0.003 \\
& Finite element & Type 3 ball & 138.3 & -0.004 \\
& analysis & Type 4 ball & 131.8 & -0.001 \\
& & Type 5 ball & 115.5 & -0.005 \\
& & Type 6 ball & 91.6 & -0.008 \\
& & Type 7 ball & 88.9 & -0.006 \\
\hline
\end{tabular}

The radial force was calculated from the analyses of the $\mathrm{Cu}$ tube expansion, and the expansion force was calculated in the axial direction. There is linear correlation between the ratio of the radial force to the expansion force and the tube's inner groove deformation. This suggests that the tube's inner groove deformation becomes larger when the difference between the radial and expansion forces is larger (Figure 10). In this correlation analysis, Type 4 was excluded because the tube's inner groove peaks do not contact the expansion ball surface.

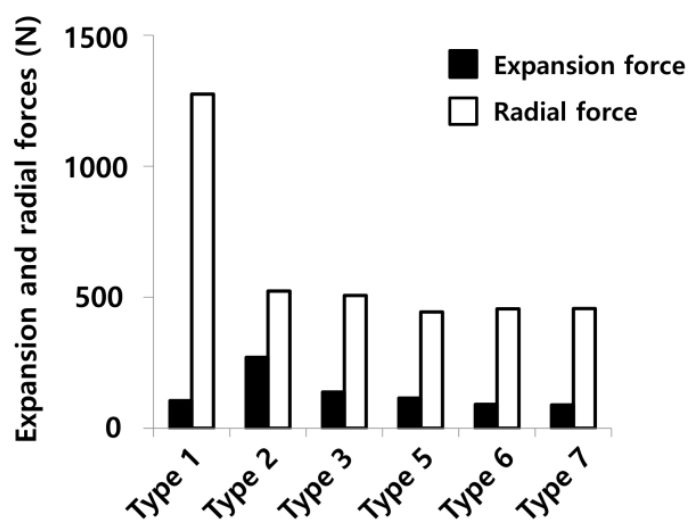

(a)

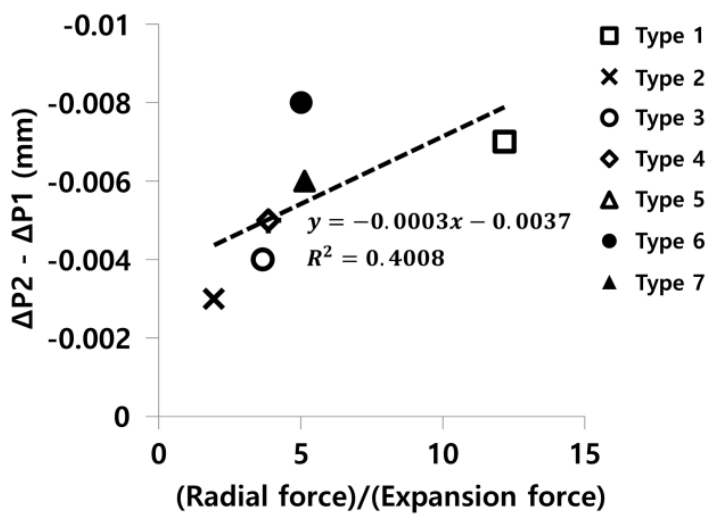

(b)

Figure 10. (a) Expansion and radial forces from Types 1-7 except Type 4, where the tube's inner groove does not contact the expansion ball; and (b) correlation between the deformation of the tube's inner grooves and the radial force divided by the expansion force. 


\section{Conclusions}

This study determined the dominant variables of the tube expansion process as well as the expansion ball shape design that greatly influence the tube expansion performance and analyzed their role on the expansion performance. The $\mathrm{Al}$ tube expansion experiments showed that the amount of lubricant in the contact space between the ball and tube affected the expansion force, but there was no significant effect of the expansion speed on the expansion force. The experiment also showed that the standard deviation of the expansion force rate was proportional to the expansion force, suggesting that it influences the deformation of the tube's inner grooves.

The results of the FE analysis of the $\mathrm{Cu}$ tube expansion indicated that the number and surface width of the ball grooves played a role in increasing the expansion force when both were designed to increase the contact area between the ball and tube. The ball's radius of curvature $R$ also affected the expansion force. However, increasing the ratio of the radial force to the expansion force led to an increase in deformation of the tube's inner grooves. Further research is planned to improve the expansion performance by optimization of the expansion ball design variables based on these results.

Author Contributions: C.H. and H.K. designed and performed the experiments and FE analysis of Al tubes; I.S. performed the FE analysis of $\mathrm{Cu}$ tubes; S.P. conceived and analyzed the experiments and the FE analysis of $\mathrm{Al}$ and $\mathrm{Cu}$ tubes, and also wrote the paper.

Acknowledgments: This research was supported by the National Research Foundation of Korea (NRF) grant funded by the Korea government (MSIP) (No. NRF-2016R1A2B4012561), by Engineering Development Research Center (EDRC) funded by the Ministry of Trade, Industry \& Energy (MOTIE) (No. N0000990), and by "Human Resources Program in Energy Technology" of the Korea Institute of Energy Technology Evaluation and Planning (KETEP) granted financial resource from the Ministry of Trade, Industry \& Energy, Republic of Korea (No. 20164030201230).

Conflicts of Interest: The authors declare no conflicts of interest.

\section{References}

1. Finned Tube Heat Exchangers. Available online: http://www.enggcyclopedia.com/2012/03/finned-tubeheat-exchangers / (accessed on 12 March 2012).

2. Kim, Y.J.; Cho, J.M.; Kim, M.S. Experimental study on the evaporative heat transfer and pressure drop of $\mathrm{CO}_{2}$ flowing upward in vertical smooth and micro-fin tubes with the diameter of $5 \mathrm{~mm}$. Int. J. Refrig. 2008, 31, 771-779. [CrossRef]

3. Almeida, B.; Alves, M.; Rosa, P.; Brito, A.; Martins, P. Expansion and reduction of thin-walled tubes using a die: Experimental and theoretical investigation. Int. J. Mach. Tools Manuf. 2006, 46, 1643-1652. [CrossRef]

4. Pervez, T.; Qamar, S.Z.; Al-Abri, O.S.; Khan, R. Experimental and Numerical Simulation of In-Situ Tube Expansion for Deep Gas Wells. Mater. Manuf. Process. 2012, 27, 727-732. [CrossRef]

5. Tang, D.; Li, D.; Peng, Y.; Du, Z. A new approach in evaluation of thermal contact conductance of tube-fin heat exchanger. Appl. Therm. Eng. 2010, 30, 1991-1996. [CrossRef]

6. Avalle, M.; Priarone, P.C.; Scattina, A. Experimental and numerical characterization of a mechanical expansion process for thin-walled tubes. J. Mater. Process. Technol. 2014, 214, 1143-1152. [CrossRef]

7. Scattina, A. Numerical analysis of tube expansion process for heat exchangers production. Int. J. Mech. Sci. 2016, 118, 268-282. [CrossRef]

8. Karrech, A.; Seibi, A. Analytical model for the expansion of tubes under tension. J. Mater. Process. Technol. 2010, 210, 356-362. [CrossRef]

9. Lee, S.-M.; Park, B.-D. Heat transfer characteristics of the non-uniform grooved tube considering tube expansion. Korean J. Air-Cond. Refrig. Eng. 2012, 24, 553-559. [CrossRef]

10. Seibi, A.; Barsoum, I.; Molki, A. Experimental and numerical study of expanded aluminum and steel tubes. Procedia Eng. 2011, 10, 3049-3055. [CrossRef]

11. Liu, Y.; Qiu, X. A theoretical study of the expansion metal tubes. Int. J. Mech. Sci. 2016, 114, 157-165. [CrossRef]

12. Alves, M.; Almeida, B.; Rosa, P.; Martins, P. End forming of thin-walled tubes. J. Mater. Process. Technol. 2006, 177, 183-187. [CrossRef] 
13. Tang, D.; Li, D.; Peng, Y.; Du, Z. Mechanical Expansion of Thick-Walled Microgroove Tube for High Pressure ACR System. J. Press. Vessel. Technol. 2011, 133, 021202. [CrossRef]

14. Tang, D.; Peng, Y.; Li, D. Numerical and experimental study on expansion forming of inner grooved tube. J. Mater. Process. Technol. 2009, 209, 4668-4674. [CrossRef]

15. Al-Abri, O.S.; Pervez, T.; Qamar, S.Z.; Al-Busaidi, A.M. Optimum mandrel configuration for efficient down-hole tube expansion. J. Manuf. Sci. Eng. 2015, 137, 061005. [CrossRef]

16. Madhusudana, C.; Cheng, W.-W. Decrease in thermal contact conductance and the contact pressure of finned-tube heat exchangers assembled with different size bullets. J. Heat Transf. 2007, 129, 907-911. [CrossRef]

17. Kwon, H.; Kim, K.-H.; Han, C.; Park, S. A new methodology for detecting adhesion location in aluminum tube expansion. Adv. Mech. Eng. 2017, 9. [CrossRef]

18. Chahardoli, S.; Nia, A.A. Investigation of mechanical behavior of energy absorbers in expansion and folding modes under axial quasi-static loading in both experimental and numerical methods. Thin-Walled Struct. 2017, 120, 319-332. [CrossRef]

19. Reference Tables-Coefficient of Friction. Available online: http://www.engineershandbook.com/Tables / frictioncoefficients.htm (accessed on 21 September 2007).

(C) 2018 by the authors. Licensee MDPI, Basel, Switzerland. This article is an open access article distributed under the terms and conditions of the Creative Commons Attribution (CC BY) license (http://creativecommons.org/licenses/by/4.0/). 